\title{
Monitoring the Hearing Handicap and the Recognition Threshold of Sentences of a Patient with Unilateral Auditory Neuropathy Spectrum Disorder with Use of a Hearing Aid
}

\author{
Aline Patrícia Lima ${ }^{1}$ Erika Barioni Mantello ${ }^{1}$ Adriana Ribeiro Tavares Anastasio ${ }^{1}$ \\ ${ }^{1}$ Department of Ophthalmology, Otorhinolaryngology and Head \\ and Neck Surgery, University of São Paulo, Ribeirão Preto, \\ São Paulo, Brazil \\ Int Arch Otorhinolaryngol 2016;20:185-188.

\begin{abstract}
Address for correspondence Erika Mantello, PhD, Fga, Department of Ophthalmology, Otorhinolaryngology and Head and Neck Surgery, Ribeirão Preto Medical School, University of São Paulo, Av Bandeirantes 3600, Campus Ribeirão Preto, São Paulo 14049-900, Brazil (e-mail: erikafga@yahoo.com.br).
\end{abstract}

\begin{abstract}
Keywords

- auditory perceptual disorders

- retrocochlear diseases

- rehabilitation

- acoustic stimulation

Introduction Treatment for auditory neuropathy spectrum disorder (ANSD) is not yet well established, including the use of hearing aids (HAs). Not all patients diagnosed with ASND have access to HAs, and in some cases HAs are even contraindicated.

Objective To monitor the hearing handicap and the recognition threshold of sentences in silence and in noise in a patient with ASND using an HA.

Resumed Report A 47-year-old woman reported moderate sensorineural hearing loss in the right ear and high-frequency loss of $4 \mathrm{kHz}$ in the left ear, with bilateral otoacoustic emissions. Auditory brainstem response suggested changes in the functioning of the auditory pathway (up to the inferior colliculus) on the right. An HA was indicated on the right. The patient was tested within a 3-month period before the HA fitting with respect to recognition threshold of sentences in quiet and in noise and for handicap determination. After HA use, she showed a 2.1-dB improvement in the recognition threshold of sentences in silence, a $6.0-\mathrm{dB}$ improvement for recognition threshold of sentences in noise, and a rapid improvement of the signal-to-noise ratio from +3.66 to $-2.4 \mathrm{~dB}$ when compared with the same tests before the fitting of the HA.

Conclusion There was a reduction of the auditory handicap, although speech perception continued to be severely limited. There was a significant improvement of the recognition threshold of sentences in silence and in noise and of the signal-to-noise ratio after 3 months of HA use.
\end{abstract}

\section{Introduction}

Auditory neuropathy spectrum disorder (ANSD) can be defined as abnormal function of the vestibulocochlear nerve-VIII cranial pair-that generates loss of synchrony in the nerve conduction of the sound stimulus and is very probably related to a change in the myelination of these fibers. ${ }^{1}$

received

September 27, 2014 accepted

November 14, 2014

published online

January 5, 2015
The aim of the study was to monitor the hearing handicap and the recognition threshold of sentences in quiet and in the presence of noise in a patient with ANSD using a hearing aid (HA).

\section{Literature Review}

The treatment for ANSD has not been fully established, including the use of an $\mathrm{HA}$, a cochlear implant (CI), and a

Copyright $\odot 2016$ by Thieme Publicações License terms Ltda, Rio de Janeiro, Brazil

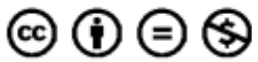


brainstem implant. ${ }^{2}$ The use of an HA may be contraindicated in ANSD because if outer hair cells are preserved, they may be damaged by amplification. ${ }^{3}$ In adults with ANSD, an HA only improves sound detection by amplification, with a minimum benefit for discrimination. ${ }^{4}$ In other studies, however, good responses have been observed with the use of both $\mathrm{HA}$ and $\mathrm{CI}$, with improved hearing and communication skills, the latter of which is one of the main complaints of these patients. ${ }^{5}$

The present case is notable because few cases of unilateral ANSD have been reported in the literature. ${ }^{6}$

\section{Case Report}

A 47-year-old woman reported bilateral hearing loss, worse in the right ear and the presence of tinnitus of the whistling and buzzing type in this same ear, along with marked speech discrimination difficulty in the presence of noise and discomfort in the presence of intense sounds. The hearing loss had started $\sim 5$ years before and progressed with time.

After evaluations and otorhinolaryngologic examination, HA adaptation was performed. Conventional pure tone audiometry and high-frequency audiometry revealed mean hearing thresholds ( $500 \mathrm{~Hz}$ to $4 \mathrm{kHz}$ ) within normal limits, with a descending configuration in the left ear and moderate sensorineural hearing loss in the right ear (-Figs. 1 and $\mathbf{2}$ ).

Speech audiometry was applied to the speakerphone. Speech recognition threshold was 55-dB hearing level (dBHL) in the right ear and $10 \mathrm{dBHL}$ in the left ear. Speech discrimination index score was $56 \%$ for monosyllables and $68 \%$ for disyllables in the right ear and $92 \%$ for monosyllables in the left ear.

Immittance testing revealed bilateral type A curve and absence of ipsilateral and contralateral acoustic reflexes at all frequencies.

Otoacoustic emissions (OAE) testing documented the presence of transient OAE in both ears.

Audiometry brainstem response (ABR) testing showed morphology, absolute latency, and interwave latency within normal limits in the left ear. Abnormal morphology was observed in the right ear at $100 \mathrm{dBHL}$, with the presence of only the $\mathrm{V}$ wave and prolonged absolute latency. The results suggested a change in the functioning of the auditory pathway up to the inferior colliculus on the right.

Nuclear magnetic resonance sequences for the visualization of the eighth pair and of the inner ear showed normal aspect, with no evidence of bilateral expansive lesions and no

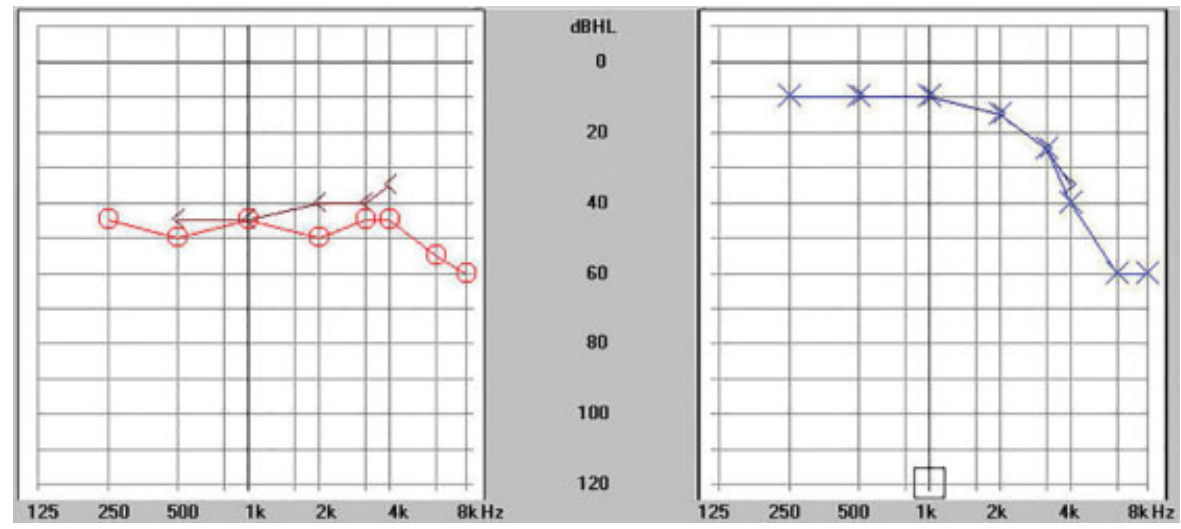

Fig. 1 Pure tone audiometry. Abbreviations: dBHL, decibels hearing levels; $\mathrm{O}$, air conduction, right ear; $\mathrm{X}$, air conduction, left ear; <, bone conduction, right ear; >, bone conduction, left ear.

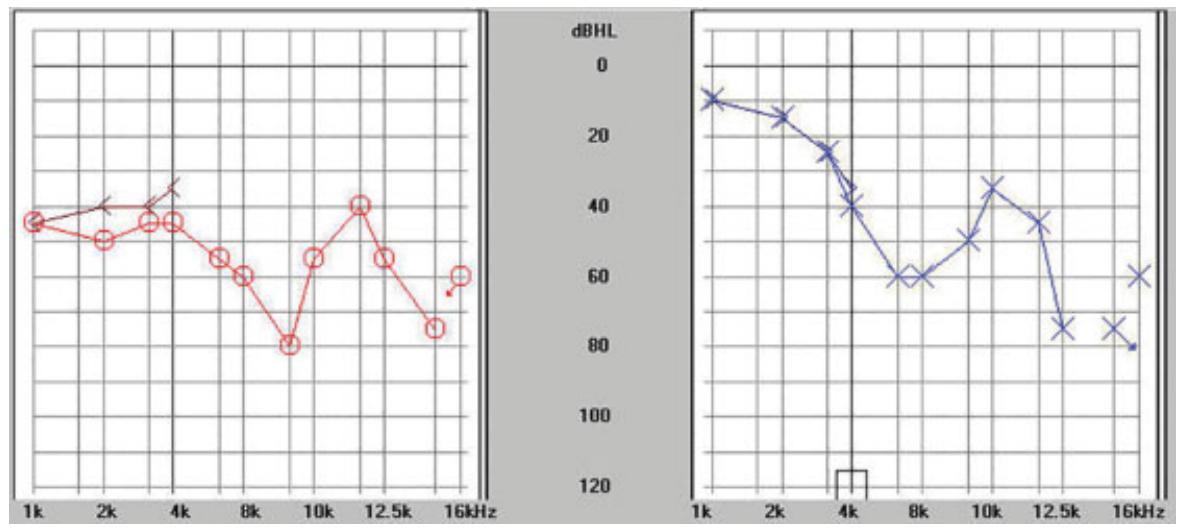

Fig. 2 High-frequency audiometry. Abbreviations: dBHL, decibels hearing levels; O, air conduction, right ear; $\mathrm{X}$, air conduction, left ear; <, bone conduction, right ear; >, bone conduction, left ear. 
Table 1 Recognition threshold of sentences in silence and in noise, percentage of correct sentences, and S/R of the patient before and after hearing aid use

\begin{tabular}{|c|c|c|c|c|c|}
\hline & LRSS & $\%$ & LRSR & $\%$ & $S / R$ \\
\hline Before hearing aid use & 46.6 & 50 & 68.66 & 40 & +3.66 \\
\hline 1 mo after hearing aid use & 48.5 & 60 & 63 & 40 & -2 \\
\hline 2 mo after hearing aid use & 43 & 60 & 63 & 50 & -2 \\
\hline 3 mo after hearing aid use & 44.5 & 60 & 62.6 & 50 & -2.4 \\
\hline
\end{tabular}

Abbreviations: LRSS, recognition threshold of sentences in silence; LRSR, recognition threshold of sentences in noise; \%, percentage of correct sentences; $S / R$, signal-to-noise ratio.

pathologic reinforcement. No changes in the membranous portions of the labyrinth were seen.

Recognition threshold of sentences in silence (RTSS) and in noise (RTSN) were obtained ${ }^{7}$ : for RTSS, a 1.9-dB increase was observed during the first month of HA adaptation and an improvement of $3.6 \mathrm{~dB}$ and $2.1 \mathrm{~dB}$ in the subsequent months compared with RTSS before HA adaptation. For RTSN, there was a 5.6-dB improvement in the first and second months after HA use and a 6.0-dB improvement 3 months later. These results demonstrate a progressive improvement in the signalto-noise ratio $(\mathrm{S} / \mathrm{N})$, which progressed from +3.66 to $-2.4 \mathrm{~dB}$. The tests were applied in an acoustic booth in a free field. Sentences and noise were on a CD in independent channels and were presented using a CD player coupled to an audiometer. These data are presented in -Table 1.

The Hearing Handicap Inventory for Adults (HHIA) was applied in the interview format before HA adaptation and after 3 months of HA use. ${ }^{8}$ The evaluation of perception of hearing handicap before HA adaptation demonstrated that all responses were attributed to the "always" option regarding both the emotional and social subscales, corresponding to a severe degree of perception (100 points). Three months after HA adaptation, there was a 40-point reduction of hearing handicap, although perception continued to be of a severe degree. The patient had follow-up once a month for 4 months for guidance on listening skills, use of lipreading, and hearing aid use.

\section{Discussion}

The percentage rate of speech recognition, the combined results of abnormal $A B R$, and the presence of transient $O A E$ in the right ear, together with the patient's complaints, support the evidence of hearing loss due to retrocochlear, and not cochlear, changes. ${ }^{1,9}$ There was hearing loss with changes in speech recognition that limited both the affectiveemotional and social life of the patient, who reported social isolation during anamnesis and in her responses to the HHIA.

Although the perception of the hearing handicap continued to be strongly present 3 months after adaptation of the $\mathrm{HA}$, the patient reported a clear improvement and was able to return to activities that she long had been unable to perform. However, she continued to report discomfort in the presence of intense sounds and noise.
Positive $^{5,10}$ and negative $\mathrm{e}^{3,4}$ reports have been published in the literature regarding the use of an HA in ANSD. In the present case, the use of an HA was of significant benefit to the patient, with an important improvement of RTSS, RTSN, and $\mathrm{S} / \mathrm{N}$ ratio in a free field. We did not find any study using the Sentence List Test in Portuguese to evaluate patients with ANSD, ${ }^{7}$ and therefore we cannot compare our findings. The positive result in the present case reflects the importance for an individual with ANSD to understand speech in silence and in noise, as these tests permit an analysis of auditory skills within a context close to the daily auditory experiences. $^{11}$

The lack of improvement in RTSS 30 days after the use of the HA may be explained by acclimatization. ${ }^{8}$ In contrast, an important improvement in RTSN was observed as early as the first month of HA use. Thus, we believe that HA use in this patient with ANSD mainly contributed to the relief of the major complaint of affected individuals (i.e., auditory speech perception in a noisy environment). $5,10,12,13$

The present findings agree with previous reports that suggested that, if the use of the HA shows some benefit in free field tests, in speech perception tests, or in terms of the user's self-evaluation, its use should be considered positive. ${ }^{5,10,12}$ On this basis, new strategies should be added or modified to improve speech comprehension and communication.

\section{Final Comments}

After 3 months of HA use, the patient showed a significant reduction of hearing handicap and an improvement in RTSS, RTSN, and S/N ratio.

\section{References}

1 Berlin CI, Hood LJ, Morlet T, et al. Multi-site diagnosis and management of 260 patients with auditory neuropathy/dys-synchrony (auditory neuropathy spectrum disorder). Int J Audiol 2010;49(1):30-43

2 Sharma A, Cardon G, Henion K, Roland P. Cortical maturation and behavioral outcomes in children with auditory neuropathy spectrum disorder. Int J Audiol 2011;50(2):98-106

3 Doyle KJ, Sininger Y, Starr A. Auditory neuropathy in childhood. Laryngoscope 1998;108(9):1374-1377 
4 Hood LJ. Auditory neuropathy/auditory dys-synchrony: new insights. Hear J 2002;55:17-18

5 Madden C, Rutter M, Hilbert L, Greinwald JH Jr, Choo DI. Clinical and audiological features in auditory neuropathy. Arch Otolaryngol Head Neck Surg 2002;128(9):1026-1030

6 Podwall A, Podwall D, Gordon TG, Lamendola P, Gold AP. Unilateral auditory neuropathy: case study. J Child Neurol 2002;17(4):306-309

7 Henriques MO, Costa MJ. Reconhecimento de sentenças no ruído, em campo livre, em indivíduos com e sem perda auditiva. Rev Cefac 2011;13(6):1040-1047

8 Lima II, Aiello CP, Ferrari DV. Correlações Audiométricas do Questionário de Handicap Auditivo para Adultos. Rev CEFAC 2010; 12:1-1

9 Zhang Q-J, Lan L, Shi W, et al. Unilateral auditory neuropathy spectrum disorder. Acta Otolaryngol 2012;132(1):72-79
10 Dell'aringa AHB, Esteves MCBN, Dell'aringa AR, Arruda GV. Hearing Aid Fitting Results in a Case of a Patient with Auditory Neuropathy. Int Arch Otorhinolaryngol 2009;13(1): 107-110

11 Oliveira JRM, Kuchar J, Valarelli TP. Estratégias de Comunicação Utilizada por Indivíduos com Neuropatia/Dessincronia Auditiva. Rev CEFAC 2011;13:85-91

12 Marino MV, Mantello EB, Valadão MN, Reis ACM, Anastasio ATR. Avaliação da contribuição do aparelho de amplificação sonora no espectro de neuropatia auditiva: um estudo de caso. Rev Med 2013;46:36-46

13 Costa NTO, Martinho-Carvalho AC, Cunha MC, Lewis DR. Habilidades auditivas e comunicativas no espectro da neuropatia auditiva e mutação no gene Otoferlin: estudo de casos. J Soc Bras Fonoaudiol 2012;24(2):181-187 